\title{
APONTAMENTOS SOBRE A FORMAÇÃO E O TRABALHO DE PROFESSORES NO BRASIL - NUMA PERSPECTIVA MARXISTA
}

\author{
Maria de Fátima Rodrigues Pereira
}

(UTP/Brasil)

\begin{abstract}
RESUMO
Procede-se neste texto a apontamentos sobre a formação e o trabalho dos professores no Brasil, numa perspectiva marxista, o que nos leva a considerar o movimento histórico da formação social brasileira, em sua totalidade e contradições. Analisa-se que os professores sempre formaram uma categoria de trabalhadores "agrilhoada", controlada. Compreende-se que a degradação e o controle da formação e trabalho dos professores, com as reformas dos governos FHC e, nos governos Lula com a introdução da EaD comprovariam a tese que Braveman formulou em sua obra Trabalho e capital monopolista - sobre a degradação do trabalho produtivo; que a tendência do capitalismo ao degradar, ao simplificar e desqualificar o trabalho, aumenta o controle sobre o processo de trabalho por meio da separação das atividades de concepção e execução. Assim, estar - se -ia alterando a natureza do trabalho dos professores e a necessária formação ficaria na posse de poucos e mais comprometida com a razão instrumental controlada, agora, pelas máquinas.
\end{abstract}

Palavras-chave: formação e trabalho de professores, marxismo.

\section{NOTES ABOUT TEACHER'S LEARNING AND WORK IN BRAZIL - MARXIST PERSPECTIVE}

\begin{abstract}
This text intends to discuss some notes on formation and work of teachers in Brazil in a Marxist perspective. This leads us to consider the historical movement of Brazilian social formation in its entirety and contradictions. It is analyzed that teachers always composed a controlled category of workers. It is comprehensive that degradation and control of teachers' formation with the reforms on FHC government and, with the introduction of Distance Education on Lula's government would prove the thesis that Braverman expressed on his book Labour and Monopoly Capital about the degradation of the productive labour. The capitalism's tendency to degrade, to simplify and disqualify labour raises the control over the work process through separation of understanding and implementing activities. This way, it would be altering the teachers' labour nature, and necessary formation would be owned by a few professionals and it would be more committed to controlled instrumental reason, at this moment with machines.
\end{abstract}

Key- words: teacher's learning and work, Marxism. 


\section{Introdução}

Pode-se considerar que somente com a criação dos sistemas educativos política necessária à expansão da produção industrial e, portanto, do trabalho intensivo apareceram no Brasil preocupações mais sérias com a formação e o trabalho docente.

Os três séculos da época moderna são marcados, no ocidente, por um longo processo de produção de uma nova "forma escolar" em detrimento dos modos antigos de aprendizagem. Nesse período, ocorre a transição em que a educação se faz pela impregnação cultural para uma sociedade munida de um sistema complexo de ensino. Assim, por muito tempo ainda, iriam conviver várias formas de transmissão de conhecimento e várias instituições se ocupariam dessa tarefa, mas, à medida que os Estados nacionais, os novos "Estados docentes" foram se consolidando, passaram a absorver essas outras formas dispersas, conformando um sistema homogêneo, regulado e controlado (VILLELA, 2000, p. 97 e 98).

Ainda que o Brasil, após 1822, por conta da sua formação social agrária e trabalho escravo, tenha se atrasado no processo de montar o seu sistema de ensino, não deixou de pensar e instituir, mesmo lentamente, formas de ensino. Contou para tal com uma multiplicidade de formas e locais para fazer isto. Também, paulatinamente, o trabalho dos professores, mesmo antes de terem escolas para sua formação foi sendo conformado por meio de pré-requisitos, com finalidades, entre as quais, as nomeações, as demissões, supervisões, direções, regulamentações, o uso de métodos de trabalho. Efetivamente, a primeira lei do Brasil independente - A Lei das Escolas de Primeiras Letras de 15 de outubro de 1827 cuja intenção foi expandir instrução, conforme o tempo do projeto iluminista burguês - não tratou da criação de um sistema de educação. $O$ dispositivo legal tratou da expansão das escolas rudimentares de leitura, de escrita, de gramática, de aritmética, de elementos de ciências sociais e naturais e definiu que o trabalho docente teria que ser organizado conforme o "ensino mútuo" "com o qual se esperava acelerar a difusão do ensino atingindo rapidamente e a baixo custo grande número de alunos" (SAVIANI, 2007, p. 128). Alves, fazendo a defesa histórica do ensino mútuo, retoma Hegel, para apontar que este entendia esse método como: “[...] além de uma desejável experiência educacional um típico empreendimento da racionalidade capitalista inglesa" (ALVES, 2005, p. 116). O método mútuo, também chamado de método monitorial ou lancasteriano, foi criado pelos ingleses - Andrew Bell, pastor da Igreja anglicana, e Joseph Lancaster - e contava com o trabalho de alunos mais avançados como auxiliares do professor com classes numerosas (SAVIANI, 2007, p. 128). Já se gastava pouco, contava-se com poucos professores. Um professor atendia um número razoável de alunos. Entre o professor e os estudantes estava o trabalho dos alunos mais avançados. De certo modo uma "precarização" do 
trabalho de ensinar. Condições do tempo? Sim, ainda se estava no início da expansão da educação, mas, fazia-se o trabalho como um "típico empreendimento capitalista".

À medida que, no Brasil, as elites de produtores agrícolas consolidavam o seu poder, e na passagem de um trabalho com mão de obra escrava para um trabalho livre assalariado consolidando as relações capitalistas de produção, a educação vai aparecendo como o grande instrumento de criação da nação. Pare e passo cuida-se da criação e implementação de uma instituição para a formação de professores que se materializou nas Escolas Normais. A primeira escola normal a ser criada foi a de Niterói em 1835. Por conta do Ato Adicional de 1834, que remeteu a instrução para a responsabilidade dos governos das provinciais, foram criadas Escolas Normais. Estas Escolas foram caracterizadas pela intermitência e precariedade no seu funcionamento. A escola de Niterói foi fechada por Couto Ferraz em 1849, quando governou a província do Rio de Janeiro. "Para ele as Escolas Normais eram muito onerosas, ineficientes em relação ao número de alunos que nelas se formaram" (SAVIANI, 2007, p. 133). Defendia a formação na prática. Por isso, já antecipava na província do Rio de Janeiro a solução adotada no Regulamento de 1854 - o Decreto Lei n. 1.331-A, de 17 de fevereiro de 1854 - que aprovou o "Regulamento" para a reforma do ensino primário e secundário do Município da Corte e a substituição das Escolas Normais pelos professores adjuntos (colaboradores, como hoje falamos). O princípio da racionalidade do tempo é dinheiro já presidia às definições para a formação de professores e que predomina até hoje. Na verdade, o trabalho docente e o ensino ainda não interessavam, não eram necessários à classe e suas frações que detinha a condução da vida societária brasileira.

\section{Formação e trabalho agrilhoados}

A escolha dos candidatos a professores fazia-se levando em conta nacionalidade, idade, conduta moral, "morigeração", "bons costumes". O atestado de boa conduta passado pelo juiz de paz do domicílio do candidato era condição para entrar na Escola Normal. Mais peso para a morigeração do que para o saber ler e escrever (VILLELA, 2000, p. 20). A propósito da moral burguesa, em A situação da Classe Trabalhadora na Inglaterra, Engels diz: "Nunca vi uma classe tão profundamente imoral, tão incuravelmente corrupta e inteiramente minada de egoísmo, tão incapaz do mínimo progresso, como a burguesia inglesa [...]. Para ela só o dinheiro conta, vive exclusivamente para ganhar dinheiro. A única felicidade que conhece é a de fazer uma fortuna rápida, e o único sofrimento o de perder dinheiro" (ENGELS, 1986, p. 311).

A intermitência na vida das Escolas Normais foi sendo superada paulatinamente. As escolas já existentes foram se consolidando e outras foram criadas. A formação de professores acelerou-se ao final do século XIX e durante toda a República Velha. Isto decorreu das mudanças na base produtiva brasileira, caracterizadas pelas primeiras 
tentativas de industrialização, de incorporação de trabalho nas máquinas, de processos produtivos já muito racionalizados que presidiu à revolução industrial o que exigia a expansão da educação. Em linhas gerais, na República Velha (1889-1930) a instrução pública era entendida como prioridade para a formação da nação agora livre do trabalho escravo. Era preciso para além de nacionalizar o estrangeiro, "civilizar" as populações negras e mestiças e prepará-las para o mundo do trabalho que, vagarosamente, iniciava a entrada nos processos industrializados. Tratava-se de "regenerar" as populações brasileiras tornando-as "saudáveis", prepará-las para hábitos de trabalho e transformar a infância abandonada em trabalhadores. Debatia-se, também, entre os vários projetos de nação - alguns fortemente influenciados pelo positivismo e sua ideologia de ordem, progresso e ciência - a ampliação dos colégios eleitorais nos Estados e a mudança do voto com base na posse da terra para o voto daquele que sabia ler. O que exigia a alfabetização e a instrução (Reforma Benjamin Constant, 1890). Tratava-se da educação do caráter, da educação cívica, da educação física. Mas a educação religiosa e moral já não davam conta, o Estado assumia a Educação para formar a nação (a constituição de 1891 separou o Estado e a Igreja e determinou que a educação deveria ser laica). O regime, e também a instrução popular, foram descentralizados, fosse, como diz Saviani, pela influência do modelo norte-americano, fosse, principalmente, pelo peso do poder econômico do setor cafeeiro que desejava a diminuição do poder central em favor do mando local. Este desejo de descentralização também se expressa quanto ao ensino formal, pois as reformas elaboradas na década de 1920 ocorreram no âmbito dos Estados.

No contexto da República Velha, as Escolas Normais começavam atingir a sua estabilidade de funcionamento e a formação de professores passou a ser mais disciplinada, conformada e estruturada.

Estranha, insólita e controversa profissão a de professor. Trabalhando com a infância e a juventude, com o objetivo de preparar o futuro, a função docente foi historicamente uma profissão normalizada, ciclicamente criticada de reprodutora e fixista. Tradicionalmente nóbil, a função docente congregou num intelectual informado e metódico as marcas do clérigo, do nobre, do cívico urbano, dos actos, com o desígnio de recuperar e transformar a sociedade, oscilando entre mestre, instituidor e oficial, e ficou modelada no professor. Assente na premissa fundante de um profissional autônomo e responsável, esta é porventura, das profissões mais regulamentadas (MAGALHÃES, 2008).

O professor, um trabalhador aguilhoado a normas, a métodos, a inspeções, a avaliações.

Se até aos primeiros anos da República (proclamação em 1889) o acesso ao trabalho docente dependia da boa "morigeração" dos candidatos, agora era a formação racional na ciência que daria conta de formar os bons professores para o trabalho docente. A formação de professores e seu trabalho passam a ser disciplinados nos métodos da ciência. A base é a biologia, a higiene. O Professor recebia em seus ombros a responsabilidade de regenerar a raça, dirigir os "incultos", instruir para controlar a 
criminalidade, formar operários, formar a nação. De um total de 540, durante o Império, o número das Escolas Normais pula na República para 1494 (XAVIER, RIBEIRO, NORONHA, 1994, p. 193). Era preciso formar o operário, conformá-lo às novas necessidades do mundo produtivo. Tratava-se de um trabalho com timbre: não a formação para o trabalho dos donos do seu suor e dos frutos do seu trabalho, mas da alienação através do controle do tempo, do disciplinamento, dos conteúdos sob uma lógica formal.

O capital operou, por dentro do Estado, de maneira descentralizada durante a República Velha e de forma centralizada durante a Era Vargas, lá com a ideologia do racionalismo, aqui com a ideologia da homogeneização da nação. Durante o Estado Novo, Vargas fecha as escolas e prende os professores das escolas étnicas. Era preciso obter "consentimento" em torno de um único projeto, o da expansão e consolidação do capital. A classe trabalhadora defendeu-se como podia. Para a educação dos seus filhos, criou as "escolas modernas". Ciência e técnica juntas, preparação para o domínio teórico e prático do trabalho e da política. Neste sentido, os socialistas que defendiam os ideais de justiça, igualdade e distribuição de riqueza no Brasil e a escola pública, fundam as Escolas Operárias e as Bibliotecas Populares. Igualmente, os anarquistas, a partir ainda da primeira década do século XX, incentivaram a criação das Escolas Modernas ou Racionais. (XAVIER, RIBEIRO, NORONHA, 1994, p.135-137).

$\mathrm{Na}$ década de 30, refunda-se a formação e o trabalho dos professores, com o movimento dos pioneiros (1932). "Na visão do 'Manifesto' o professor seria um educador de larga visão que, dotado de espírito científico, lançaria mão de todas as técnicas disponíveis desenvolvidas cientificamente para impulsionar a administração dos serviços escolares" (SAVIANI, 2007, p. 242). Incorporava-se ao trabalho dos professores o "diferente", o método intuitivo, os museus pedagógicos, a recreação, a literatura seriada de formação (Monteiro Lobato). A educação volta-se também, como antes, para os indivíduos, não para sujeitos pertencentes a classes. Funda-se, conforme o Manifesto, "no "caráter biológico" que permite, a cada indivíduo, se educar, conforme é de seu direito, até onde permitam as suas aptidões naturais, independente de razões de ordem econômica e social" (SAVIANI, 2007, p. 243).

Em 1939, em pleno Estado Novo, foi criado o curso de Pedagogia instituído por ocasião da organização da Faculdade Nacional de Filosofia. Na sua estrutura o curso de pedagogia iniciou já padecendo de um "mal” que o acomete até hoje e sobre o qual já tanto se escreveu e tantos remédios foram tentados. Trata-se do eixo que o sustenta, da natureza do seu ser - o fragmento - manifesto na separação da "teoria" e da "prática" da "forma" e do "conteúdo", das "disciplinas de conteúdos" e da "didática". A famosa estrutura 3+1 que também contaminou as licenciaturas. Tratava-se do bacharelato e da licenciatura. O primeiro para as ciências, o segundo para o método; o primeiro para os conteúdos, o segundo para os instrumentos. Esta divisão aponta para uma concepção dicotômica de ciência e de método, que não articula conteúdo e processo. É evidente, 
nesta configuração que ficou conhecida por $3+1$, a separação entre conteúdo e método de ensino, entre teoria e prática. Então, o princípio que presidiu à organização não é o da relação intrínseca entre a formação e o trabalho. Tanto assim que houve a maior dificuldade em definir o campo de trabalho dos bacharéis e dos licenciados, pois, não tinham o trabalho no curso normal como campo exclusivo da atuação. "Isto porque a Lei Orgânica do Ensino Normal - o decreto-lei n. 8.530/ 46 - estabelecia que, para lecionar nesse curso, era suficiente, em regra, o diploma de ensino superior" (SILVA, 2003, p.14). Daí que, nos cursos normais, poderiam trabalhar médicos, juristas, entre outros.

Do "mal" da dicotomia, da separação do fragmento, os cursos de formação de professores não se curaram. Ao contrário, este mal tem se acentuado, apesar dos muitos diagnósticos feitos por tantos de nós que têm dedicado suas vidas de professores pesquisadores à melhoria do ensino. Efetivamente, muito se tem escrito sobre a formação e o trabalho docente. Igualmente é ampla a produção sobre os cursos de pedagogia. Esta produção já constitui um acervo que foi construído nos debates, nas pesquisas, nas formulações de políticas sem o qual não se poderia ir além. Tal como em Saviani, vemos “[...] se não se domina o já conhecido não é possível detectar o não conhecido [...] (1987, p. 51). Está no conhecido a possibilidade de produzir o novo. Mas, precisamos dizer que é na prática da vida que está a verdade. E a verdade é que a formação de professores não está dando conta de formar trabalhadores em educação qualificados para o ensino do patrimônio historicamente acumulado pela humanidade, fundamental para a produção de explicações que viabilizem a superação do modo capitalista de produção.

No Parecer 252/69, Valnir Chagas, ao fixar os mínimos do currículo e do tempo de duração para o curso de graduação em pedagogia, começa a propor a formação do especialista no professor - para as atividades de orientação, administração, supervisão e inspeção no âmbito de escolas e sistemas de ensino. Esta posição permite subentender, que, o parecerista considerava que existiam atribuições na escola que o professor não dominava e que precisava de quem o orientasse. Nesta lógica, o professor não era concebido como alguém que tinha que dominar os instrumentos, processos, espaços e relações que envolvem o ensino e a aprendizagem (BRASIL, CFE, Documenta, n. 100, p. 110. APUD, SILVA, p. 31). É o fragmento recheado de tecnicismo, do qual nós ainda não nos livramos. Uma concepção que põe por terra um projeto de formação baseado no domínio do conhecimento, de forma a permitir a explicação do modo de existência nas suas múltiplas dimensões - históricas, econômicas, políticas, da ciência, da técnica, da arte e do movimento. Recordando Saviani, "O trabalho educativo é o ato de produzir, direta e intencionalmente, em cada indivíduo singular, a humanidade que é produzida histórica e coletivamente pelo conjunto dos homens" (SAVIANI, 2003, p. 13). A negação de uma formação que dê conta desta tarefa traz ônus à humanidade. 
Na década de 70, além de ter sido superada a formação tecnicista, acentuou-se a precarização da formação. O que foram as licenciaturas "curtas" senão o tempo apoucado na formação de professores? Não volta agora, sob outro discurso, esta formação em nada, sob o manto do tempo curto da produção de mercadorias como as cargas horárias mínimas, sem nunca se falar das necessárias? Não volta com certas modalidades de educação à distância, que se configuram em meras certificações de professores-técnicos e colaboradores? Muda-se o discurso para dar a aparência da mudança, o capitalismo remenda-se, reforma-se para continuar sua caminhada.

O que vemos é que na maioria dos cursos de formação de professores, houve uma degradação. As suas configurações, os procedimentos formativos não estão centrados no concreto, no real: a totalidade, grávida de contradição, entre o projeto de educação burguesa, para quem sempre houve muita educação, e o projeto da grande maioria desprovida de meios de produção, para quem só sobrou a apoucada possibilidade de se humanizar. Para muitos o trabalho alienado, para poucos o usufruto dos bens socialmente produzidos.

Com a reestruturação produtiva em curso desde a década de 1980, a nova divisão do trabalho, as políticas dos organismos mundiais (Banco Mundial, FMI) a formação e o trabalho dos professores foram postos em quarentena. Sofreram reformas, no conjunto da reforma do Estado brasileiro. Nunca antes e com tanta intensidade, quanto nos governos FHC, se controlou, agrilhoou e precarizou a formação do professor e o seu trabalho. Chamaram-se assessorias estrangeiras (Espanha, França) e professores de renome do cenário educativo brasileiro. O resultado foi uma formação dos professores que não repousa mais num conjunto de conhecimentos prévios, como antes (ciência, métodos). A formação não assenta, mais, em conhecimentos disciplinares e científicos como os instituídos pela face racionalista do projeto burguês em curso a partir dos princípios iluministas. $\mathrm{O}$ ataque à escola tradicional, justificado pelo caráter antidemocrático do cientificismo da razão iluminista, tecnicista, operacional, hoje incluiu a desconfiança dos conhecimentos científicos. Mas, se de um lado se desprezam os conhecimentos científicos, coloca-se em seu lugar os princípios da organização do mercado, uma vez que o professor é um pesquisador do cotidiano, um prático assalariado ao serviço do capital (é o professor temporário, o técnico, o colaborador - de quem?) que reflete sobre as suas ações cujos objetivos estão previamente demarcados pela adequação ao mundo produtivo, tal qual ele se apresenta na reorganização do capital monopolista. Ou seja: se durante as décadas de 1960 e 1970 a formação de professores ainda assentava em princípios da ciência - que pode ou não ser posta a serviço da acumulação de capital, da racionalidade iluminista, ou também de projetos do interesse da classe trabalhadora - agora inverte - se o eixo estruturante da formação. Não são as disciplinas, os conhecimentos, mas a flexibilidade de lidar com situações que vêm do mundo da produção e do consumo. Fechou-se o cerco. A formação foi 
formatada na razão instrumental da ordem societária do capital. Ela torna-se rígida nos eixos estruturantes das demandas e flexível nas respostas dentro dessas demandas.

Compondo este quadro de aligeiramento da formação e de alienação do trabalho de professores, observamos que a oferta de formação de professores tem crescido substancialmente na Educação a Distância (EaD). Em 2006 quando de um total geral de 818.580 vagas oferecidas para cursos na modalidade a distância, 524.096 foram para educação, portanto, 64\%02: sendo 18.912 em instituições públicas e 505.184 pelo setor privado (DOURADO, 2008, p. 901). Trata-se da implantação da expansão da formação de professores pela EaD. O censo de 2009 (p. 65) informa que o curso de Pedagogia a distância representa $23 \%$ da EaD que atende majoritariamente a sujeitos com renda até três salários mínimos o que demonstra que $\mathrm{EaD}$ é dirigida essencialmente a famílias pobres.

Todo este processo foi acompanhado por políticas do MEC para a área, intensificado ao final do primeiro governo Lula e caracterizadas por parcerias entre as IES públicas e privadas, a atribuição de importante protogonismo da Capes, Inep e SEED (PEREIRA, PEIXOTO, FORNALSKI, 2010). Vejamos: 1. em 2005, o ministério inclui na sua agenda o Fórum com as Estatais pela Educação cujo objetivo foi a criação do sistema Universidade Aberta do Brasil (UAB) para atuação na formação inicial e continuada de professores da educação básica com a utilização de metodologias de educação a distância; 2. no ano seguinte, pelo Decreto n. 5.800, o MEC instituiu o Sistema Universidade Aberta do Brasil, ligada à Capes, em pareceria com a SEED; Com a articulação entre IES públicas de ensino superior, estados e municípios, a UAB propõe-se a expandir e levar aos interiores do Brasil cursos de educação superior pública, para gestores e trabalhadores, de educação básica e apoiar pesquisas sobre EaD. Em 2007, foram selecionados 27 pólos para atenderem a 673 turmas e 32.880 vagas. No mesmo ano esta política de formação a distância de professores foi fortalecida com a atribuição a CAPES coordenação do Sistema Nacional de Formação, ao INEP o papel de acompanhar, e ao FNDE, de financiar; sobretudo, para a formação de professores. No mesmo ano, o MEC, por meio da SEED estabeleceu novos Referenciais de Qualidade para EaD, reforçando (1) a necessidade dos cursos a distância se pautarem pelo Projeto Político Pedagógico, (2) a atenção que devem merecer os estudantes, (3) a interação professor-aluno, coordenadores, equipe administrativa, o material didático, instalações.

Adotar a EaD na formação inicial e continuada de professores não seria como expressou Saviani (1995, p. 22) ao se referir à escola nova, adotar um "mecanismo de recomposição da hegemonia da classe dominante para desenvolver um tipo de ensino adequado aos seus interesses?" .

Compre-se com a atual formação e trabalho de professores a tese que Braveman formulou em sua obra Trabalho e capital monopolista - sobre a degradação do trabalho material; que a tendência do capitalismo ao degradar, ao simplificar e desqualificar o 
trabalho aumenta o controle sobre o processo de trabalho por meio da separação das atividades de concepção e execução. Estaria assim, alterando-se a natureza do trabalho não material dos professores e a necessária formação estaria na posse de poucos e mais comprometida com a razão instrumental controlada agora pelas máquinas?

Estamos mais longe da formação e do trabalho de professores que a classe trabalhadora necessita para revolucionar suas condições de existência?

\section{Bibliografia}

ALVES, Gilberto Luiz. O trabalho didático na escola moderna. Formas históricas. Campinas: Autores Associados, 2005.

ASSOCIAÇÃO BRASILEIRA DE EDUCAÇÃO A DISTANCIA (ABED). Censo EAD. br. 2009. Relatório analítico da aprendizagem a distância no Brasil. São Paulo: Pearson Education do Brasil, 2011.

DOURADO, Luiz Fernandes. Políticas e Gestão da Educação Superior a Distância: novos marcos regulatórios? In: Educação\& Sociedade, Campinas, vol. 29, n. 104 Especial, p. 891-917, out. 2008. Disponível em http://www.cedes.unicamp.br.

ENGELS, Friederich. A Situação da classe trabalhadora na Inglaterra. São Paulo. Global Editora, 1988.

MAGALHÃES, Justino. O PROFESSOR: Um regenador agrilhoado. In: Revista Histedebr on line, n. 31. www.histedbr.fae.unicamp.br.revista.

MARX, Karl; ENGELS, Friederich. A Ideologia alemã. Crítica da filosofai alemã mais recente na pessoa dos seus representantes Feuerbach, Bruno Bauer e Stirner, e do socialismo alemão na dos seus diferentes processos. Lisboa: Editorial Presença/ Livraria Martins Fontes.

PEREIRA, M. F.. PEIXOTO, E. M.. FORNALSKI, R.. Educação a distância com novas Tics: que cidadania/que ontologia? Comunicação no Seminário AFIRSE, Lisboa, 2010.

SAVIANI, Dermeval. Escola e democracia. São Paulo: Autores Associados, 1995.

Pedagogia Histórico Crítica. Campinas: Autores Associados,

2003.

Associados, 2007.

História das idéias pedagógicas no Brasil. Campinas: Autores

SILVA, Carmen Silvia Bissolli. Curso de Pedagogia no Brasil. História e Identidade. Campinas: Autores Associados, 2003. 
VILLELA, Heloísa de O. S. O Mestre escola e a professora. In: LOPES, Eliane Marta Teixeira, Faria FILHO, Luciano Mendes, VEIGA, Cynthia Greive. 500 anos de educação na América. Belo Horizonte: Editora Autêntica, 2000.

XAVIER, Maria Elizabeth; RIBEIRO, Maria Luisa; NORONHA, Olinda Maria. História da educação: a escola no Brasil. São Paulo: FTD, 1994.

Recebido em: $10 / 12 / 10$

Aprovado em: 13/02/11 